\title{
PEDRO ROCHE ARNAS, IN MEMORIAM
}

\author{
Bernardo Bayona Aznar
}

El 3 de marzo de 2015 falleció en Madrid Pedro Roche Arnas, a los 71 años, sin haber podido disfrutar de la jubilación, a la que había accedido un año antes, porque en seguida le apareció un cáncer insuperable.

El profesor Pedro Roche fue socio fundador de la Sociedad Española de Filosofía Medieval en 1990 y participó muy activamente en todas las actividades de la SOFIME, de la que fue director desde 2004 hasta 2012. Organizó y dirigió el Vº Congreso de Filosofía Medieval, sobre «Pensamiento político en la Edad Media», celebrado en Alcalá de Henares en diciembre de 2008; y codirigió con Josep Puig el XIX Coloquio Anual de la Sociedad Internacional para el Estudio de la Filosofía Medieval (SIEMP), con el tema «Legitimation of Political Power in Medieval Thought», que se celebró igualmente en Alcalá en septiembre de 2013.

Nacido en Albalate del Arzobispo (Teruel), el 21 de junio de 1943, pudo estudiar porque a los once años fue enviado al Seminario Menor de la diócesis en Alcorisa (Teruel), como tantos otros niños de pueblo que no tenían otra oportunidad para estudiar en aquella larga postguerra. De allí pasó al Seminario Mayor de Zaragoza y, en 1962, tras haber cursado ya cinco años de Humanidades y tres de Filosofía, marchó a la Universidad Pontifica de Salamanca, donde se graduó como Bachiller en Filosofía (título específico de las Universidades Pontificas equivalente al actual Grado) y obtuvo la licenciatura en Filosofía y Letras, Sección Filosofía. Realizó cursos de doctorado en esta misma Universidad y, posteriormente, en la Universidad Complutense de Madrid, en la que obtuvo el título de Doctor en Filosofía y Ciencias de la Educación en 1990, tras décadas de docencia en la Enseñanza Media y de gestión educativa.

En 1967 aprobó las oposiciones a Profesor Agregado de Institutos Nacionales de Enseñanza Media y al año siguiente las de Catedrático de Enseñanza Media. Ante la carencia de posibilidades de acceder a la docencia universitaria en aquella época, los egresados más preparados y con mejor expediente, si carecían de otros recursos familiares, solían opositar a este prestigioso cuerpo, que era entonces el segundo cuerpo docente del Estado y en el que iniciaron su carrera académica no pocos de los más brillantes catedráticos de la Universidad española de las décadas siguientes. Ejerció como profesor de Filosofía de Bachillerato en los Institutos Nacionales de Enseñanza Media de Albacete (1967-69); Peñarroya-Pueblonuevo (Córdoba, 1969-74); «Práxedes Mateo Sagasta», de Logroño (1974-80); «Goya», de Zaragoza (1980-1995, estando en situación administrativa de «servicios especiales» desde 1983); e «Isabel la Católica», de Madrid (1995-2004). En su primer destino, Albacete, también enseñó Filosofía en el Colegio Universitario. Y, desde el curso 1995 a 2002, compatibilizó su cátedra en el Instituto de Enseñanza Secundaria «Isabel la Católica» con una plaza de profesor asociado en el Departamento de Historia I y Filosofía de la Universidad de Alcalá; primero, a tiempo parcial y, luego, a tiempo completo, en aplicación de un convenio de la Comunidad de Madrid. En 2004 fue nombrado profesor contratado Doctor y, finalmente, obtuvo plaza de profesor titular en esa misma Universidad.

De espíritu inquieto e inconformista y con un intenso sentido de la justicia, Pedro Roche albergaba, además, un animoso sentimiento de cooperación y un acuciante sentido de la responsabilidad, que lo llevaron a comprometerse en la lucha por reformar los espacios de trabajo 
a los que pertenecía. Ya en sus años de estudiante salmantino fue nombrado delegado sindical de la Pontificia Universidad, planteando reivindicaciones y participando en reuniones, algunas clandestinas, como una celebrada en Barcelona en 1965, por la que sería públicamente recriminado. En los últimos años de la dictadura franquista y durante la transición a la democracia fue secretario general de la Asociación Nacional de Catedráticos de Bachillerato (ANCABA); se afilió a FETE (UGT), cuando consiguió convencer a la ejecutiva de este sindicato de la justicia de sus reivindicaciones; y, en los últimos años, participó activamente en la Fundación Educación y Ciudadanía, impulsada por Luis Gómez Llorente dentro del sindicato socialista. Desde 1983 hasta 1987 desempeñó la función de director provincial del Ministerio de Educación y Ciencia en Teruel. En esta ciudad formó parte de los Patronatos del Colegio Universitario y de la Universidad de Verano y fue miembro fundador del Centro Asociado de la UNED, de cuyo Patronato fue vicepresidente. Luego, entre 1987 y 1996, ejerció como subdirector general de direcciones provinciales del MEC, encargándose de coordinar, supervisar y facilitar el trabajo de los directores provinciales de la mayor parte de España hasta las transferencias de las competencias educativas a todas las Comunidades Autónomas. Por último, como docente universitario, fue miembro del Claustro y de la Mesa del Claustro de la Universidad de Alcalá y de la Junta de la Facultad de Filosofía de esa Universidad.

Pedro Roche mantuvo dos grandes preocupaciones a lo largo de toda su dedicación a la educación, como profesor y como gestor: la dignificación de la escuela rural y la conexión entre el profesorado de Bachillerato y el de la Universidad.

Como responsable de la administración educativa la actuación de la que se sentía más orgulloso fue la creación de los Centros Rurales de Innovación Educativa (CRIETs), como un instrumento para apoyar la escuela rural. El profundo amor por su tierra y su fe en la educación lo llevaron a comprometerse y a trabajar para que todos los niños de los pueblos más pequeños tuvieran las mismas oportunidades de estudiar y de progresar en la vida que el hijo de la elite más privilegiada. Se propuso mantener abiertas todas las escuelas, aunque el número de alumnos fuera muy pequeño, y dotarlas de calefacción y de medios. Un pueblo sin escuela, repetía una y otra vez, es un pueblo muerto. Su profundo sentido de lo público, y en especial, su actitud hacia la escuela pública, le incitaban - decía - a devolver a la sociedad lo que la sociedad le había dado. Por ello, encarnó la transformación de la escuela rural en la democracia con nuevas ideas, con proyectos concretos, y apoyándose siempre en las personas. Expresaba así esta confianza, en un emotivo artículo, «Colegio Gloria Fuertes: pasión y compromiso», publicado en el libro El colegio de la luz (Zaragoza, 2008): «...teníamos algo de un extraordinario valor, disponíamos del mejor caudal: maestras y maestros conocedores del rumbo que debíamos imprimir y, al mismo tiempo, profundamente comprometidos e implicados en su difícil y complejo trabajo; maestras y maestros convencidos de que la educación es el principal instrumento con que cuentan las personas para su realización personal y las sociedades para su desarrollo, cohesión e integración; maestras y maestros sabedores de que la búsqueda de la equidad entendida como igualdad de oportunidades ante la educación obligatoria debe aspirar a la igualdad de resultados y que, por ello, exigió, y exige, actuaciones educativas preferentes destinadas a compensar positivamente determinadas desigualdades de origen».

A la valoración de los CRIETs dedicó su tesis doctoral. Y, en reconocimiento a su actividad gestora en el ámbito educativo no universitario, el Ministerio de Educación le concedió la Encomienda con Placa de la Orden al Mérito Docente de Alfonso X el Sabio y el Gobierno de Aragón la Cruz José de Calasanz al Mérito Educativo.

La segunda preocupación era el reconocimiento del mérito y capacidad de los profesores de Bachillerato de los antiguos cuerpos de Enseñanza Media para poder acceder a la docencia universitaria. Como secretario general de ANCABA, Pedro Roche negoció con los diferentes 
ministros de Educación (Íñigo Cavero, Ortega y Díaz Ambrona o Mayor Zaragoza) el desarrollo de dos artículos de la Ley General de Educación de 1970: el art. 115.2, que reservaba el $50 \%$ de las plazas de catedráticos de Escuelas Universitarias para concurso de méritos entre catedráticos de Bachillerato; y art. 117, que posibilitaba su participación en oposiciones restringidas a plazas de Agregados de Universidad. Ninguno de aquellos ministros de la UCD fue capaz de sacar la Ley de Autonomía Universitaria (LAU). Y en 1983, siendo ya director provincial de Educación en Teruel, consiguió, por mediación de quienes éramos ponentes parlamentarios de la Ley de Reforma Universitaria (LRU), que el artículo 39.4 de esta ley abriera los concursos de méritos para plazas de Escuelas Universitarias a los Catedráticos de Bachillerato, aunque la decisión quedaba en manos de las Universidades, que nunca activaron esa posibilidad. Esta batalla fue una obsesión de Pedro Roche, pero él no buscaba solo una promoción personal, sino el reconocimiento de una carrera docente para los profesores de Bachillerato, pues cuando ya era profesor universitario, siguió luchando, infructuosamente, por la unidad de todos los niveles del sistema educativo, incluso en la tramitación de la actual Ley Orgánica de Universidades (LOU).

El investigador universitario Pedro Roche centró su actividad investigadora, principalmente, en la historia del pensamiento político medieval cristiano, más concretamente, en el pensamiento teocrático y en las reacciones contra este, en especial, a comienzos del siglo XIV. De hecho, el $V^{\circ}$ Congreso Internacional de la SOFIME y el XIX Coloquio Anual de la SIEMP, ambos organizados por él, versaron sobre la relación entre los dos poderes, el eclesiástico o religioso y el civil o temporal. Sobre el conflicto doctrinal por la supremacía del poder entre la Corte Francesa y el Papado en torno a 1300, trató también su participación en otros Congresos y Coloquios. Así, fue ponente en el XVII Coloquio Anual de la SIEMP, celebrado en Porto Alegre (Brasil) en 2010, con «Quaestio in utramque partem, o sobre la autonomía del poder real in temporalibus»; y en varias ocasiones presentó comunicaciones sobre el pensamiento teocrático de Egidio Romano: «La plenitudo potestatis en el De ecclesiastica potestate de Egidio Romano» (XI Congreso Internacional de Filosofía Medieval, Oporto, 2002); «Iglesia y poder en el De ecclesiastica potestate de Egidio Romano» (I Congreso Iberoamericano de Ética y Filosofía Política, Alcalá de Henares, 2002); «Temporalia et dominium ecclesiae en el De eclesiástica potestate de Egidio Romano» (IV Congreso Nacional de Filosofía Medieval, Córdoba, 2004). En los últimos años trabajó, en el contexto de esa misma polémica doctrinal, sobre la teoría de los dos poderes en Juan de París y sobre la obra anónima Rex Pacificus; y acudió al VI ${ }^{\circ}$ Congreso Internacional Iberoamericano de Filosofía Medieval (2012, Salamanca) con «Autonomía in temporalibus y preeminencia social del poder laico en el anónimo Rex pacificus Salomon». Y, desde 2006, realizó todos los años estancias de un mes en el Instituto de Investigación en Filosofía Medieval Raimundus-Lullus-Institut de la Universidad de Friburg.

De sus publicaciones sobre el pensamiento medieval cabe mencionar la coordinación del libro El pensamiento político en la Edad Media (Madrid, 2010) y la edición con B. Bayona de las obras menores de Marsilio de Padua. Sobre el poder del Imperio y del Papa. El Defensor Menor y La Transferencia del Imperio (Biblioteca Nueva, 2005). Colaboró asimismo en otras obras colectivas con trabajos como: «El fin último del hombre según Avempace», en Pensamiento medieval hispano. Homenaje a Horacio Santiago-Otero, v. II (CSIC, Madrid, 1998); «¿Qué es filosofía para Avempace?», en Was ist Philosophie im Mittelalter (Walter de Gruyter, Berlín-New-York, 1998). En esta Revista Española de Filosofía Medieval tiene publicado los artículos: «La Ley en el Defensor Minor de Marsilio de Padua» (n² 2, 1995); «Una lectura medieval del intelecto activo de Aristóteles» ( $\left.n^{\circ} 10,2003\right)$; «San Agustín y Egidio Romano: de la distinción a la reducción del poder temporal al poder espiritual» $\left(\mathrm{n}^{\circ} 15,2008\right)$. Y en diversas revistas académicas especializadas: «La Plenitudo Potestatis en el Defensor Minor de Marsilio de Padua» (Éndoxa, $\mathrm{n}^{\circ}$ 6, 1995, UNED); «Iglesia y poder en el De ecclesiastica potestate de Egidio 
Romano» (Anales del Seminario de Historia de la Filosofía (n ${ }^{\circ} 24,2007$, Universidad Complutense); o «Al César lo que es del César. Dos lecturas sobre el poder temporal: Hugo de san Víctor y Egidio Romano» (Patristica et Mediaevalia, $\mathrm{n}^{\circ}$ 31, 2010, Universidad de Buenos Aires).

Sobre cuestiones educativas, publicó el libro Los Centros Rurales de Innovación Educativa de Teruel (C.R.I.E.T.s): respuesta de futuro a la nueva escuela rural (I.C.E. de la Universidad de Zaragoza, 1993), y es coautor, con B. Bayona y otros, de la obra La Enseñanza de la Filosofía en B.U.P. y C.O.U: visión de alumnos y profesores (I.C.E. de la Universidad de Zaragoza, 1982), aparte de escribir variados artículos en revistas educativas y periódicos.

Pero del profesor Pedro Roche hay que destacar que, si le importaba la filosofía, más le importaban los alumnos. Le satisfacía especialmente el reconocimiento de los estudiantes, que le otorgaban las evaluaciones más altas. Cada año recibía una carta de felicitación de la Vicerrectora de Calidad e Innovación de la Universidad de Alcalá y la felicitación fue aún mayor y más gratificante en octubre de 2010: «por los excelentes resultados obtenidos en las encuestas docentes en los últimos cinco años». Por ese motivo los estudiantes lo elegían y reelegían para impartir la lección final de su graduación en el Paraninfo de Alcalá de Henares. Y, por ello, no solo los compañeros, los cargos académicos y el rector anterior, sino también, y sobre todo, los representantes de los alumnos lo recordaron con emoción y agradecimiento en el espléndido y entrañable acto de homenaje que le rindió la Universidad de Alcalá en ese mismo recinto cisneriano, al mes siguiente de su muerte, solo unos días después de la entrega del Premio Cervantes de 2105.

Además de un profesor apreciado, un gestor responsable y un investigador notable, Pedro Roche era, sobre todo, una gran persona, un hombre noble. Los que tuvimos la suerte de tenerlo como compañero y amigo sabemos bien de su generosidad para facilitarnos las cosas, de su constancia en los afectos y de su lealtad indeleble. Quizá era también lealtad lo que le impedía dejar atrás todo lo que había sido su pasado, desde su pueblo en el que quiso ser enterrado hasta la Universidad en que acabó su vida profesional, pasando por el amor a la jota, el recuerdo de su juvenil Salamanca, el aprecio al cuerpo de catedráticos de Instituto, o el arraigo en las instituciones a las que sirvió, como el Colegio Mayor Cerbuna de Zaragoza, los distintos Institutos de Enseñanza Media o el Ministerio de Educación.

Como le costaba mucho desprenderse de las vivencias, despedirse de los amigos, abandonar el pasado, marcharse de los sitios, tampoco tuvo nunca prisa por llegar a nuevos estadios vitales, sino que entraba en ellos como se recoge la fruta en sazón: en la docencia universitaria, en el matrimonio con Lola, su compañera y amiga desde el Instituto Sagasta de Logroño, o en la paternidad. Por eso, cuando había cumplido todos esos estadios, se negaba a la evidencia de que, al final, tenía que irse tan de prisa, sin que la vida le diera ni siquiera el tiempo de ver terminar medicina a su hija Ana, la niña de sus ojos. 